Forum 2017 · 32:272

DOI 10.1007/s12312-017-0260-8

Online publiziert: 26. April 2017

(c) Springer Medizin Verlag GmbH 2017

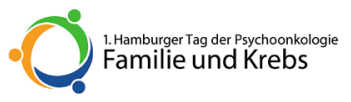

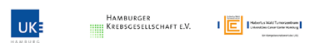

\section{„Familie und Krebs" - so lautete das Thema des 1. Hamburger Tages der Psychoonkologie, der gemeinsam von der Hamburger Krebsgesellschaft, dem Institut und Poliklinik für Medizi- nische Psychologie und dem UCCH ver- anstaltet wurde.}

Rund 150 Teilnehmer aus den Fachgebieten der Psychoonkologie, Psychologie, Psychotherapie, Onkologie u.a. folgten am 24. Februar der Einladung des Instituts und Poliklinik für Medizinische Psychologie, der Hamburger Krebsgesellschaft und des UCCH zum 1. Hamburger Tag der Psychoonkologie.

„Als wir uns für das Thema „Familie und Krebs" als Start dieser Reihe entschieden hatten, wagten wir nicht zu hoffen, dass es auf derartige Resonanz stoßen würde. Schon nach wenigen Wochen war die Tagung mitsamt allen Workshops ausgebucht. Es kann also keinen Zweifel daran geben, dass die Aspekte, die hinter dieser Tagung stehen, von großer Relevanz sind“, sagt Prof. Martin Härter, Direktor des Instituts und der Poliklinik für Medizinische Psychologie in seinem Grußwort.

In vier verschiedenen Workshops konnten sich die Teilnehmer über Themen bezüglich Familie und Krebs in kleineren Gruppen austauschen, am Nachmittag gab es ein gemeinsames Programm im Erika-Haus mit Key Notes zum Praxisalltag und wissenschaftlichen Themen.

„Wir von der Hamburger Krebsgesellschaft freuen uns sehr, dass wir gemeinsam mit dem UKE so ein Projekt auf die Beine stellen konnten. Wir sehen es in der täglichen Praxis, dass in der Begleitung von Krebserkrankten und ihren Angehörigen auch der Austausch unter den Fachexperten unbedingt stattfinden muss", so PD Dr. Georgia Schilling, Geschäftsführerin der Hamburger Krebsgesellschaft e.V.

Hamburger Krebsgesellschaft e.V., Hamburg

\title{
1. Hamburger Tag der Psychoonkologie
}

„Wir haben über die Jahre Erfahrungen in der Begleitung von Familien und besonders von Kindern gesammelt - es ist eine Freude, diese Erfahrungen zu teilen und mit den Teilnehmern über ihre Beobachtungen zu diskutieren", sagt Dr. Frank Schulz-Kindermann, Leiter der Spezialambulanz für Psychoonkologie am UKE.

Die Fachtagung soll jährlich mit unterschiedlichen Schwerpunktthemen wiederholt werden.

\section{Kontakt}

Hamburger Krebsgesellschaft e.V.

Butenfeld 18

22529 Hamburg

Tel. $04041347568-0$

info@krebshamburg.de

www.krebshamburg.de

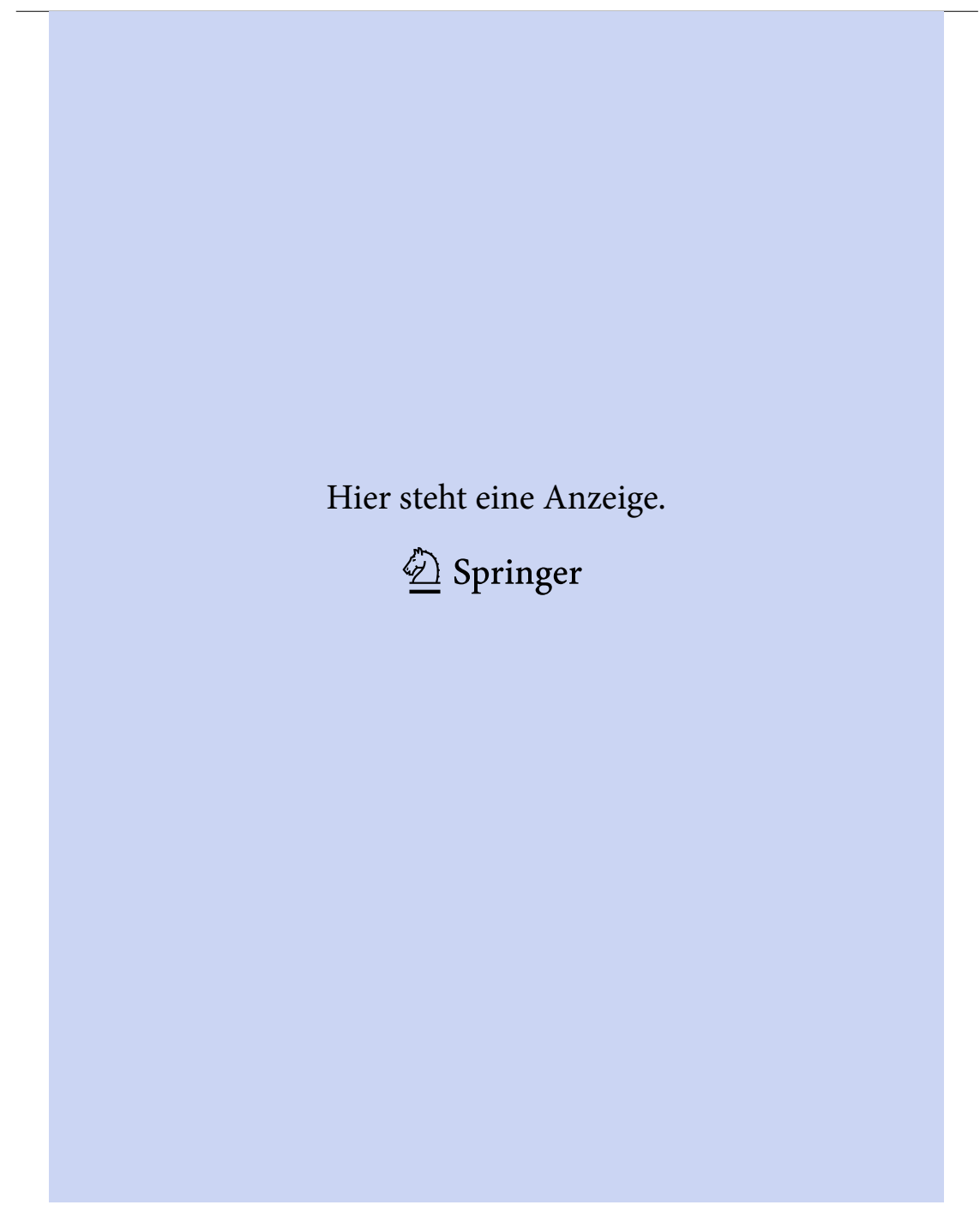

